\title{
INVESTIGATION OF METHODS OF PROTECTIVE COATINGS APPLICATION ON THE ROTOR OF DOWNHOLE DRILLING MOTOR
}

\author{
• • одорезов, • • ролов, • • вет шов, • • еонтьев, • • толбов \\ D. D. Vodorezov, S. A. Frolov, V. N. Svetashov, D. S. Leontiev, O. M. Stolbova \\ ксперимент льный з вод буровой техники юменского индустри льного университет , г. юмень \\ лючевые слов : 3 шитные покрытия; 2 зотермическое н пыление; л зерное опл вление \\ Key words: protective coatings; gas-thermal spraying; laser melting
}

процессе эксплу т ции винтового з бойного двиг теля в условиях скв жины происходит интенсивный износ его р бочих орг нов, приводящий к изменению их н ч льных технических (геометрических) п р метров и к к следствие к снижению энергетических х р ктеристик двиг теля в целом [1]. p боте [2] были отмечены причины недост точно высокого ресурс винтовых з бойных двиг телей ( $)$ : бр зивный износ р бочих орг нов ( ), огр ниченный темпер турный ди п зон р боты эл стомеp ст тор , деформ ция его эл стичной обкл дки, приводящие к смещению ротор в p ди льном н пр влении под действием силовых ф кторов, т кже поперечные колеб ния ротор и корпус двиг теля. бр зивные ч стицы, н ходящиеся в буровом р створе вызыв ют износ, способствуют уменьшению н тяг в п ре и, к к следствие, обусловлив ют потери энергетических х р ктеристик двиг теля [3].

эксперимент льном з воде буровой техники юменского индустри льного университет р зр б тыв ется технология созд ния н поверхностях дет лей роторов винтовых з бойных двиг телей функцион льных, износостойких, коррозионно-стойких, нтифрикционных, нтиз дирных и теплостойких покрытий.

ервон ч льно втор ми р зр б тыв л сь линия по н несению 3 щитных покрытий дет лей «ротор винтового з бойного двиг теля» Г зопл менным способом, с д льнейшим опл влением слоем уст новкой

л нируемые пок з тели:

1) дгезия - не менее 100 ; 2) относительн я износостойкость - не менее 3,0 ;

3) пористость - менее $0,5 \%$;

4) теплостойкость - не менее $140{ }^{\circ} \mathrm{C}$;

5) толщин - не менее 0,3 мм;

6) н грузк $з$ дир - не менее 1000

7) твердость - 58-62 HRC;

8) коэффициент трения - не более 0,3

9) шерохов тость - не менее $0,8 \mathrm{R}$.

бр $б$ тыв ем я дет ль ротор предст вляет собой в л с многоз ходной винтовой поверхностью. $\quad$ р мк х исследов тельских р бот было проведено н пыление поверхностного слоя с мофлюсующегося порошк и проведено его д льнейшее опл вление 3мя способ ми: г зовой горелкой, ток ми высокой ч стоты, л зерной уст новкой.

пл вление поверхности подр зумев ет второе термическое воздействие н дет ль, что может привести к п дению конструкционной прочности дет ли (инструмент ) 3 счет снижения предел уст лостной прочности.

торое термическое воздействие может привести к выходу геометрических р змеров дет ли (инструмент ) з поле допуск , особенно это кту льно для длинномерных конструкций.

пл вление г зовой горелкой (рис. 1) з ключ ется в р зогреве поверхности до появления зерк льной поверхности, после чего необходимо нез медлительно перемещ ть г зовую горелку из р спл вленной зоны, ин че будет происходить перегрев поверхности и стек ние н пл вленного слоя. 3 ск з нного выше следует, что решение с г зовой горелкой не подходит для применения в линии, т к к к втом тизиров ть процесс перемещения г зовой горелки при появлении зерк льной поверхности сложно или попросту невозможно.

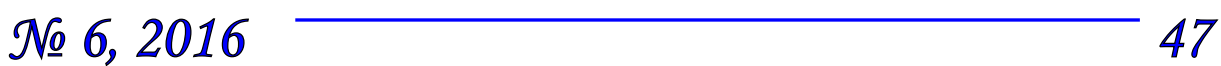




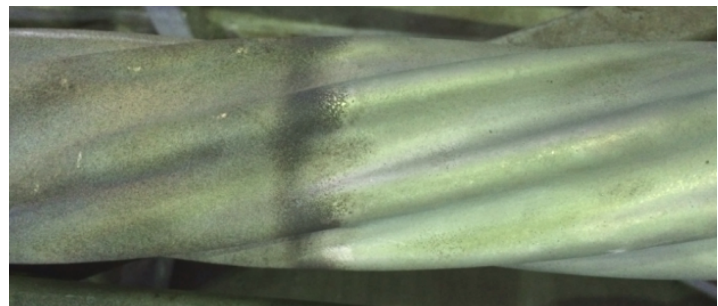

ис. 1. бор торный обр зец ротор после опл вления 2 зовой горелкой

кже н контрольно измерительной м шине

были произведены з меры профиля л бор торного обр зц до и после н пыления с д льнейшим опл влением. езульт ты з меров приведены н рисунк х 2, 3. к к к дет ль имеет форму винтовой поверхности, пятно конт кт г зовой горелки при опл влении дост точно большое происходит нер вномерный процесс опл вления. результ те чего происходит стек ние р спл вленного слоя с вершин и боковых поверхностей во вп дину. ричем с боковых поверхностей в отличие от вершин происходит пр ктически полное стек ние. тсюд следует, что добиться р вномерности поверхностного слоя с применением г зовой горелки не предст вляется возможным.

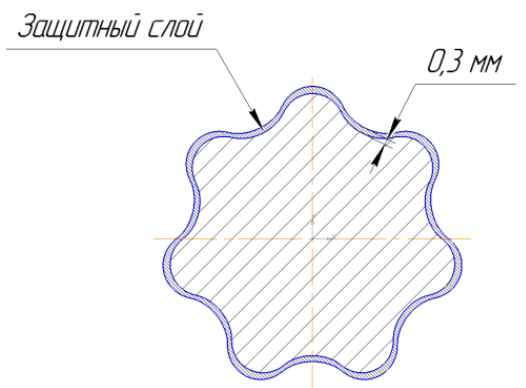

ребуемый профиль покрытия

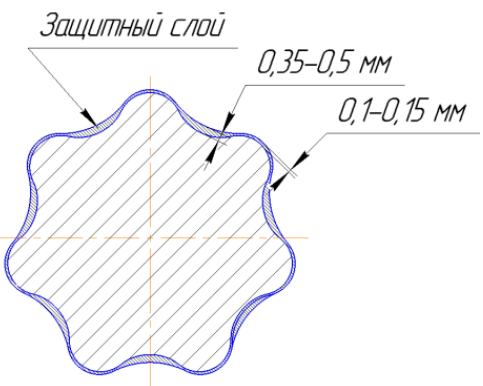

рофиль по результ т м испьт ний

ис. 2. р внение профилей л бор торного обр зи ротор

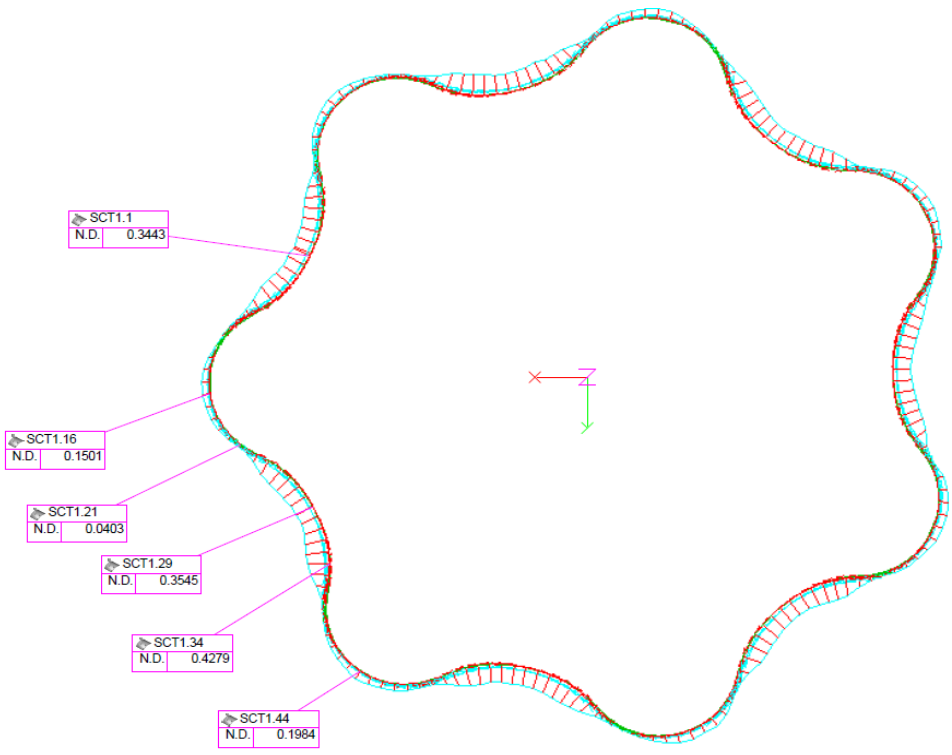

ис. 3. езульт тыз меров профиля л бор торного обр зи ротор послен пыления и д льнй шего опл вления 
лее был произведен эксперимент по опл влению л бор торного обр зц ток ми высокой ч стоты с применением кольцевого индуктор . виду сложной формы т к же, к к и в случ е с г зовой горелкой происходит перегрев вершины зубьев и стек ние опл вленного слоя во вп дину (рис. 4).

\section{ис. 4. бор торный обр зец ротор после опл вления ток ми высокой ч стоты}

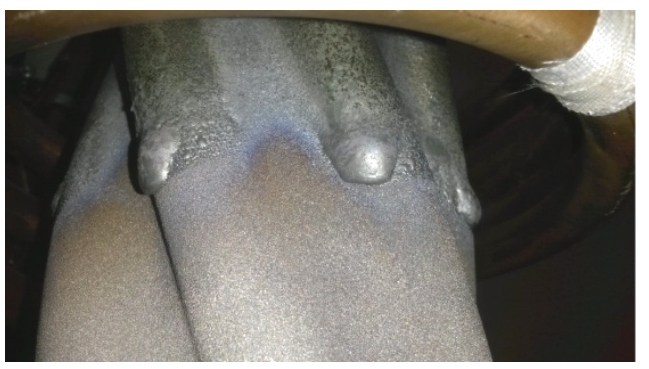

динственным в ри нтом опл вления поверхностного слоя сложного профиля дет ли ротор является опл вление лучом л зер . пл вление опытного обр зц произведено роботом м нипулятором по специ льно н пис нной прогр мме. езульт ты 3 меров приведены н рисунке 5 .

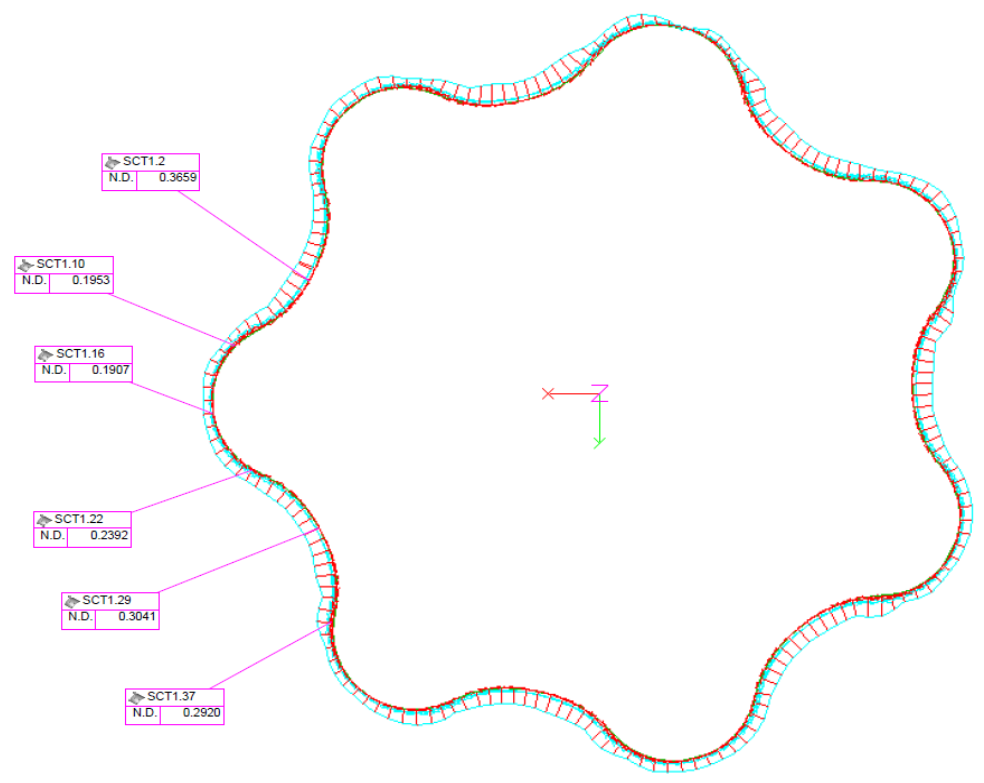

ис. 5. езульт тыз меров профиля л бор торного обр зц ротор после н пыления и д льней иего опл вления $я$ зерной уст новкой с применением робот м нипулятор

пл вление с помощью л зерной уст новки является современным и дорогостоящим способом. отличие от предст вленных выше способов опл вления, где основной мет лл подверг ется зн чительному подпл влению и термическому воздействию, что является весомым недост тком, опл вление л зером обеспечив ет миним льное тепловое влияние н дет ль. ри обр ботке л зером - н грев лок лизов н и соответствует форме, p змеру под в емого излучения, глубин термического воздействия огр ничен незн чительным приповерхностным слоем, бл год ря чему вероятность коробления (иск жения формы) дет ли минимизиров н . основным преимуществ м можно отнести:

- $\quad$ контролируемое м лое пропл вление;

- минимиз ция обл сти термического влияния (деформ ция обр б тыв емых дет лей почти отсутствует). 
ереход с технологии н несения з щитного покрытия с г зотермического способ н пыления с последующим опл влением - ток ми высокой ч стоты, н технологию н несения з щитного покрытия г зотермическим способом н пыления с последующим опл влением л зером позволит снизить уровень теплового воздействия, увеличить дгезию, т к к к связь подложки с поверхностным слоем ст новится мет ллур-

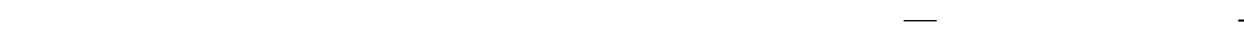
пл вленного слоя.

пл вление поверхностного слоя, н несенного г зотермическим способом с помощью лок льных энергетических источников - г зопл менных, имеет недост тки.

1. ри опл влении ток ми высокой ч стоты поверхности имеющей сложную геометрию, к к пок зыв ет пр ктик, не уд ется получить р вномерное опл вление поверхностного слоя в силу физики процесс воздействия н поверхностный слой, т к к к меняется р сстояние от индуктор до обр 6 тыв емой поверхности и соответственно изменяется энерговкл д в поверхностный слой.

2. 3 всех концентриров нных св рочных источников энергии г зовое пл мя обл д ет н именьшим зн чением коэффициент сосредоточенности.

изкое зн чение коэффициент сосредоточенности св рочного источник энергии не позволяет получить р вномерный прогрев поверхностного слоя вследствие ккумуляции тепл впереди ход движения г зового пл мени (при с мых широких в ри циях коэффициентов перекрытия). ля устр нения д нного эффект необходимо упр вление мощностью св рочного пл мени в режиме ре льного времени, что пр ктически невозможно ре лизов ть.

нный нег тивный эффект устр няется т кже тем, что г зовое пл мя созд ет в зоне обр ботки с мое низкое зн чение плотности мощности, что не позволяет обеспечив ть высокие скорости н грев и соответственно минимизиров ть тепловложение.

3. рименение электродугового св рочного источник энергии (TIG-св рк ) для перепл в приводит, в силу физики процесс , к большому зн чению коэффициент перемешив ния и соответственно к невозможности сформиров ть 3 д нные функцион льные свойств поверхностного слоя з один проход

ким обр зом, из всех вышеперечисленных концентриров нных источников энергии только луч л зер обл д ет необходимыми техническими х р ктеристик ми, позволяющими обеспечить к чественный перепл в поверхностного слоя.

ним относятся высокие плотности мощности в зоне обр ботки; высокий коэффициент сосредоточенности; возможность упр вления плотностью мощности (мощностью) в режиме ре льного времени.

ист нция л зерной оптической головки от опл вляемой поверхности сост вляет несколько десятков мм, поэтому для ре лиз ции процесс опл вления необходим робот м нипулятор, который будет с высокой точностью повторять геометрический профиль дет ли и выдержив ть 3 д нное р сстояние между дет лью и оптической головкой. ереход н г зотермический способ н пыления с опл влением л зером позволяет

- уменьшить уровень шум почти в дв р $з$ в процессе опл вления;

- увеличить дгезию;

- обеспечить р вномерность н пл вляемого слоя (что подтвержд ется проведенными эксперимент ми);

- убр ть нег тивное термическое воздействие н дет ль и к к следствие отк з ться от необходимости проводить низкотемпер турный отпуск дет ли;

- обеспечить $з$ д нную шерохов тость дет ли.

бот выполнен совместно едер льным госуд рственным бюджетным обр зов тельным учреждением высшего профессион льного обр зов ния "юменский госуд рственный нефтег зовый университет» $и$ «роизводственн я фирм окол» по комплексному проекту созд ния высокотехнологичного производств "зр ботк, проектиров ние, изготовление и монт жл линии по н несению з шитных покрытий» шифр 2014-218-05-128. роект ре лизуется з счет субсидии н госуд рственную поддержку коопер ции российских высших учебных з ведений, госуд рственных н учных учреждений и орг низ ций, ре лизующих комплексные проекты по созд нию высокотехнологичного производств, утвержденных пост новлением р вительств оссийской едер иии от 9 преля 2010 г. № 218. 
писок литер туры

1. шибков . ., войников . ., ролов . ., вет шов . ., ньков . ., лопотов . . онтроль п р метров р бочих орг нов винтовых з бойных двиг телей // естник ссоци ции буровых подрядчиков. - 2015. - № 3. $-.2-4$.

2. овенский . ., шибков . ., войников . ., ролов . . н лиз результ тов исследов ний износостойкости ротор винтового з бойного двиг теля // звестия вузов. ефть и г з. - 2014. - № 5. - . 86-88.

3. овенский . ., шибков . ., войников . ., ролов . . прочнение поверхностного слоя роторов винтовых з бойных двиг телей г зотермическими покрытиями // звестия вузов. ефть и г з. - 2014. - № 5. - . 89-91.

\section{ведения об втор $x$}

одорезов митрий митриевич, инженер ксперимент льного з вод буровой техники, юменский индустри льный университет, тел. +79068203000, e-mail:vodorezov@gmail.com

ролов ергей ндреевич, директор ксперимен$m$ льного з вод буровой техники, юменский индустрильный университет, тел. +79068203000, e-mail: frolov_72@inbox.ru

вет шов л димир икол евич, н ч льник конструкторского отдел ксперимент льного з вод буровой техники, юменский индустри льный универсиmem, тел.+792204444764, e-mail:svetashov@mai.ru

еонтьев митрий ергеевич, ссистент к федры « урение нефтяных и г зовых скв жин» 2. юмень, тел.+79323202656, e-mail:leonfob@mail.ru

толбов льг их йловн, м гистр нт, юменский индустри льный университет, тел. 89829113082 , e-mail: olga.stolbowa2013@yandex.ru

\section{Information about the authors}

Vodorezov D. D., engineer of Experimental plant of drilling technique, Industrial University of Tyumen, tel. +79068203000,e-mail:vodorezov@gmail.com

Frolov S. A., Director of Experimental plant of drilling technique, Industrial University of Tyumen, tel. +79068203000,e-mail:frolov_72@inbox.ru

Svetashov V. N., Head of the designing department of Experimental plant of drilling technique, Industrial University of Tyumen, tel. +792204444764, e-mail: svetashov@mai.ru

Leontiev D. S., assistant of the Department of «Drilling of oil and gas wells», Industrial University of Tyumen, tel. +79323202656,e-mail:leonfob@mail.ru

Stolbova O. M., master student of Industrial University of Tyumen, tel. +79829113082 , e-mail:olga.stolbowa2013 @yandex.ru 